\title{
SNAKES, TREES AND FLAMES: A DISCUSSION OF VENETIAN CURVED CORNETT DECORATIONS
}

\section{John McCann}

I am sometimes asked about the decorations on Venetian cornetts. My observations concerning them are based upon 30 years of cornett making, examination of instruments in American and European collections, and broad historical curiosity. I am aware of the shortcomings of this approach. Somewhere out there is a musicologist, an art historian or cultural anthropologist with better answers or even "The Truth." This article provides tentative answers and observations.

Venetian cornetts, which were highly prized for their exceptional quality, found their way into courts all over Europe, judging from extant inventories.

Venetian curved cornetts share a common decorative theme, especially those attributed to the Bassano family on the basis of their activities as players and makers and the "rabbit's feet" markings found on some of the instruments." (These will be called one-, two- or threemark instruments based on the number of such pairs of feet found on an instrument.)

Curved cornetts come in several sizes and forms. Ignoring the question of pitch, the curved cornett family consisted of five voices. In descending order they are: cornettino; treble (or Chorzink in German), the most common size and hereafter referred to simply as cornett; alto; tenor, and bass. (The serpent is not considered to be a member of the cornett family. ${ }^{2}$ ) The cornettino does not appear to have been used in Italy, but seems to be a later, German contrivance. ${ }^{3}$ The size of the instrument has a great influence on its form and decorative treatment.

The form of the curved cornett reflects its descent from hunting horns and fingerhole horns fashioned from cow and similar-shaped horns. Most cornetts and cornettini are made in this slightly curved shape, which not only evokes their origin but also facilitates playing by better placement of the fingerholes under the lower hand. This disregards the direction of the curve and the question of which hand is placed uppermost on the instrument. The Renaissance high-pitch cornett ( $\mathrm{a}=\mathrm{c}$. $465 \mathrm{~Hz}$.), somewhat shorter than a modern-pitch instrument, could be played with either hand in the uppermost position (though it is easier to play a right-curved instrument with the right hand in the lower position). ${ }^{4}$ Paintings reflecting left hand down on a right-curved instrument and right hand down on a left-curved instrument are sometimes seen, but artistic considerations seem predominant in such cases. 5 The high proportion of extant left-curved original instruments poses an

John McCann is a cornett maker presently living in Sandy, Utah. While studying recorder with Jeanette Chemin-Petit in Berlin, he met and was inspired by Otto Steinkopf to make cornetts, which he has pursued since 1959. 


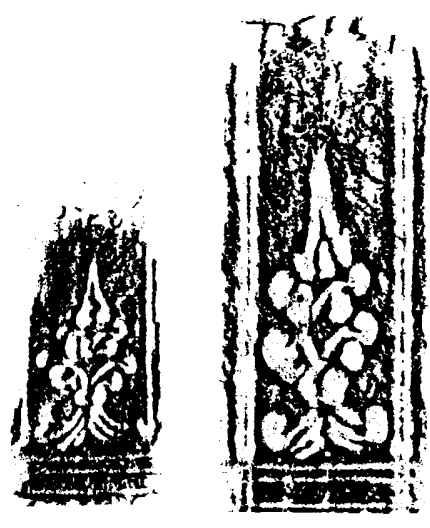

Verona 13265 (left) illustrates a typical cornett conifer, while Verona 13293 displays a typical tenor conifer.
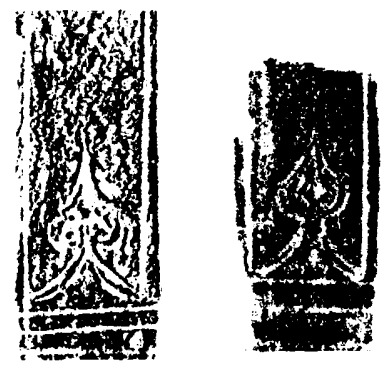

The spade resembles that figure on a playing card. It is a much simplified conifer, containing only the roots and an outline of the tree. Verona 13268 (left) and Brussels 1213 , a cornett with no extant marks, both contain this ornamentation. interesting question.

Some very few cornetts, some altos and most tenors and basses are doublecurved serpentine in form or are made in an " $S$ " shape. The serpentine-shaped instruments, like the simple curved cornetts, are made from a piece of wood cut horizontally into a top half and a bottom half, gouged out and glued together. The larger " $S$ "-shaped instruments are made from a piece of wood cut vertically into a left half and a right half. The fingerholes of the " $S$ "-shaped instruments are on the glue seam.

Musically, the cornett has sometimes been associated with the underworld. In this regard, it is unknown if decorative form followed function. Cornetts adopted features of serpents, creatures associated with the underworld. Serpentineshaped instruments often have a viper's head or some fanciful creature for the cornett bell. These instruments as well as the simple-curved cornetts almost always have the neck (mouthpiece end) of the instrument chip-carved on all facets (sides) in diamond patterns. These are believed to represent scales on the tail of the serpent. Functionally, the chip carving removes wood and may contribute to the propagation and quality of sound. The "S"-shaped larger instruments usually have no serpent-head bell but they do have the diamond carving on the neck. (By the way, it takes nearly two hours to chip-carve the 64 diamonds typically found on the neck of a cornett.) Even the color of the leather used to cover and bind the instrument together, black, is reminiscent of the underworld. Some maintain that parchment was used on Venetian instruments. ${ }^{6}$ Regardless of the material, the standard of craftsmanship is superb with virtually invisible seams being the standard.

As noted above, cornetts are made 
from one piece of wood cut in half, gouged out, glued together and covered with leather. The glues used then to fasten the two halves together were either animal glues, possibly made water-resistant by the addition of alum, or casein glues, already water-resistant. Both were known. After being glued, the instruments were reinforced by linen bindings in an attempt to deal with the glue's inadequacies. These wrappings were placed at four locations: at the mouthpiece end; just below the diamond pattern; between both sets of fingerholes, and near the bell. Moisture from playing swells the wood and subjects the glue seam to tremendous strain and subsequent separation. Accordingly, cornetts were then covered with leather. This leather, applied damp, shrinks and reinforces the glue and linen bindings. With the bore well oiled - and some luck - the instrument will hold together, creating the airtight bore critical to the cornett's functioning. In his Compendio Musicale (1677), Bartolomeo Bismantova mentions wetting the bore of a cornett with a glass of fresh water prior to playing in hot, dry weather. This is almost certainly meant to seal any cracks in the glue seam, which would allow air to escape and affect the instrument's functioning. ${ }^{7}$

Tooling of the leather over the bindings conceals and integrates the linen bindings into the instrument's decoration. In the case of the bindings, three parallel lines are tooled ring-like over each of the three lower bindings, while as many as five parallel lines are tooled ring-like into the leather covering the wider mouthpiece socket binding. This annular tooling of the lower three bindings is connected on each facet (side) by longitudinal tooling, lines parallel and close to each edge of each of the instrument's eight sides (facets).

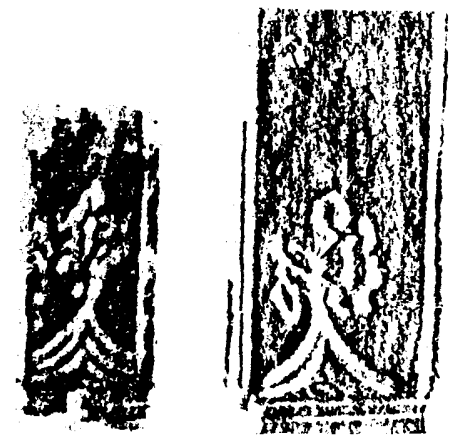

"Flaming bushes" are found on Verona 13264 (left) and Verona tenor 13292.
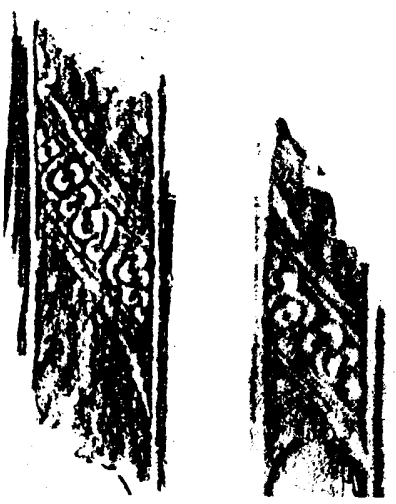

Verona 13265 (left) and Vienna 4076 contain arabesques. 


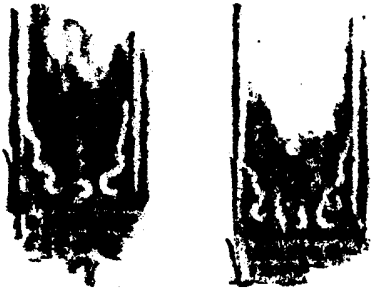

Typical instruments with squiggles are Vienna 4076 (left) and 8593.
Venetian cornetts are further decorated by tooling the leather with "blind stamping" using bookbinder's stamps. This decoration follows two general schemes, which I call "normal" Venetian and "ornate" Venetian. Aside from the annular and longitudinal lines tooled into the leather, the top facet, the surface where the fingerholes are located, has distinctive floral tooling.

Examination of a number of "normal" Venetian instruments reveals that conifer-shaped trees predominate, although there are some bushes and other patterns. These "conifers" have roots, trunk, branches and cones. They are located on the top facet near the bell, between the two sets of fingerholes and near the diamond pattern. The tree patterns appear to be made with a number of separate smaller stamps rather than a single stamp for the whole tree. Verona 13265, a two-mark instrument, illustrates a typical cornett conifer, while Verona 13293, a three-mark instrument, displays a typical tenor conifer. (See illustrations.) These conifers may represent the Mediterranean cypress (cupressus sempervirens), which is planted in Italian cemeteries and apparently has signified eternity since Roman times. If so, this is another reference to the underworld found on the instrument. (Cypress branches are also used as a symbol of mourning.)

Other designs found on Venetian cornetts are what I call the "spade" and the "flaming bush." The spade resembles that figure on a playing card. It is a much simplified conifer, containing only the roots and an outline of the tree. Verona 13268 , a two-mark instrument, and Brussels 1213, a cornett with no extant marks, both contain this ornamentation. I know of no tenors with the "spade" decoration. "Flaming bushes" are found 
on Verona 13264 and Verona tenor 13292, no-mark and three-mark instruments respectively.

"Ornate" Venetian cornetts build upon the decorations found on the normal ones. In addition to the trees, they have diagonal decorations that run between the fingerholes as well as between the fingerholes and the adjacent annular decorations. These diagonal decorations consist of a band of arabesques bounded on each side by two or three parallel lines extending to the longitudinal tooling. The arabesques are believed to be an indication of Arab influence on Venetian culture, harking back to Venice's role as a powerful trading center between Europe and the Levant.

There are many examples of ornate Venetian cornetts. Verona 13265, Vienna 4076 and 4077 (both of them twomark instruments) and Vienna 8593, which has no maker's mark, all contain arabesques. I have seen no tenors with arabesques.

Finally, on the remaining seven facets, near each of the annular bands, bounded by them and the longitudinal tooling, are found squiggles. There are about 28 pairs of squiggles on a cornett. These resemble the sound holes found on the viola d'amore. Typical instruments with squiggles are Vienna 4076 and 8593 . At an AMIS meeting some years ago in New Haven, Conn., I asked Myron Rosenblum, an internationally known authority on the viola d'amore, about the shape of the sound holes on that instrument, remarking that Venetian cornetts had a similar pattern as part of their decoration. He opined that they were of Mideastern origin, possibly representing the flaming sword of Islam. If so, this is another decorative motif borrowed from the Arab world.

Squiggles are not universal on Vene- tian cornetts. Verona 13266, a "twomark" instrument with a rather primitive conifer, has simple arcs connecting the longitudinal tooling, while Verona 13269, also a "two-mark" instrument, has twin sets of arcs. Verona 13267, a "two-mark" instrument with spades, has no tooling other than the ring tooling connecting its longitudinal lines.

The larger cornetts, such as the Venetian tenors, are decorated with the annular and longitudinal tooling, the longitudinal tooling being doubled, e.g., two parallel lines adjacent to each edge of each facet. They also have a larger version of the conifer tooled on the top facet. There are no squiggles.

As already noted, in addition to the decoration found on the Venetian cornetts, a number of instruments contain one or more sets of "rabbit's feet." This marking has been tenuously attributed to the Bassano family by some authors based upon the Bassano family's Venetian origins as players and makers. The differences in the "rabbit's feet" stamp and the numbers of "rabbit's feet" stamped on the instruments is attributed to successive generations of makers. However, there are also instruments that are clearly Venetian but lack the "rabbit's feet." There is also speculation that the number of "rabbit's feet" was an indicator of the instrument's quality.

Douglas Kirk attributes instruments signed by one pair of rabbit's feet to Hieeronymus (Jerome) Bassano, those signed by two pair to his (probably eldest) son Jacomo, and Santo Griti, and those with three pair to the English branch of the family, probably by Arthur (1547-1624) and his son, Anthony II (1579-1658). ${ }^{8}$ I have some problems with these attributions based on the form and decorations on the instruments. The earlier profile of the cornett was round. 
It would be consistent to assign the round cornetti with one pair of rabbit's feet, such as Brussels 1211 and the unnumbered round cornett in the Gorga collection in Rome, to Hieronymus. Since this round profile is the earlier form, it is difficult to attribute the two round-profile "three-mark" tenor cornetts found in the Gorga collection to the English branch of the family active from the middle of the 16th to the middle of the 17 th century.

There are five octagonal-profiled twoand three-mark tenor cornetts in the Braunschweig (one) and Verona (four) collections.

These Venetian tenors are made from maple. Presumably they would have to be subjected to microscopic examination to tell if the wood was sycamore-maple (Acer pseudoplatanus) indigenous to the British Isles, Italian maple (Acer opalus) or Turkish maple (Acer cappadocicum).

Though it is beyond the purview of this article, the chain of evidence between Venice and the Verona collection, which has direct and undisturbed provenance, is quite strong. The Braunschweig instrument, too, almost certainly came from the Braunschweig court, as did the Venetian instruments in the Museum for Hamburg History. This court had strong connections with Venice as the result of marriage. I find it hard to believe that English instruments would be "laundered" through Venice. I think they were all made in Venice. There are too many stylistic similarities.

The decorative stampings on the Christ Church cornetts, two-mark instruments, are also made with a single bookbinder's stamp as opposed to decorations made with many little stamps. They are unique in this respect for the Bassano family.

With respect to the maker's marks, I have no answers. At one time, I thought it would be possible to identify makers from the instrument patterns and the decorations. All instrument makers use patterns, and I have traced a number of instruments. Some of these tracings match up, indicating they probably came from the same workshop, but that is as far as I have carried it. Also, the decorations are unique, so that one may be able to identify individual craftsmen from their work. This would require some careful detailed analysis.

In summary, Venetian curved cornetts were superbly crafted, both musically and from workmanship perspectives. Their leather covering was decorated with distinctive tooling reflecting the instrument's association with the underworld as well as cultural influences derived from Venice's role as a major trading power.

\section{Notes}

1. David Lasocki, "The Anglo-Venetian Bassano Family as Instrument Makers and Repairers." Galpin Society Journal, No. XXXVIII, April, 1985 pp. 112-113. Also, Douglas Kirk, "Cornetti and Performing Pitch of Choirs in Northern Italy and England." The Early Brass Journal, No. 4, July 1987, pp. 3-9.

2. R. Morley-Pegge, "The Anaconda," Galpin Society Journal, No. XII, June, 1959, pp. 53-56. Morley-Pegge points out that the serpent and contrabass cornett (italics mine) are two distinct kinds of instruments based on the same acoustic principle. Differences include rate of bore expansion, wall thickness, outer profile and presence or absence of keys.

3. John McCann, "The Cornettino in Italy?" The Early Brass Journal, No. 4, July, 1988, pp. 1-2. 
4. Kirk, "Cornetti and Performing Pitch," which thoughtfully explores the question of Italian pitch. Surviving Venetian cornetti seem to fall into two groups: There are a few tutto punto instruments with a mean pitch of around $487.4 \mathrm{~Hz}$ and a larger group of mezzo punto instruments with a mean pitch of around $469.7 \mathrm{~Hz}$, about a half-step below tutto punto and about a half-step above modern $a=440 \mathrm{~Hz}$. (These pitches are derived from clusters of instruments of about the same length and should be considered approximate.)

5. See painting of cornett player and another person by G. B. Morone, c. 1526-1578, in the Galleria Capitolina, Rome, and painting "The Concert," by R. Valentin, c. 1620-1622, Louvre, Paris, which show cornett players with their hands arranged artistically rather than to suit the curve of the instrument.

6. Edward H. Tarr, "Digression on Parchment versus Leather Covering of Historical Cornetts," Basler Jahrbuch für Historische Musikpraxis, V, 1981, Das Zink Buch, pp. 17-20. This book, to which I contributed field notes, measurements and other material, including concepts of decoration, is the single most comprehensive book available on the cornett.

7. Bruce Dickey, Petra Leonards and Edward H. Tarr, "The Discussion of Wind Instruments in Bartolomeo Bismantova's Compendio Musicale (1677)"'; translation and commentary, Basler Jahrbuch for Historische Musikpraxis, II, 1978, Sonderdruck, pp. 143-187.

8. Kirk, "Cornetti and Performing Pitch."

\section{Robb Stewart Brass Instruments}

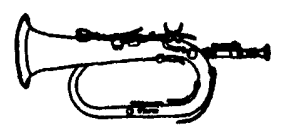

Maker of historical brass instruments. Specializing in replicas of mid-19th century American rotory valve instruments. Keyed brass including bugles, ophicleides, metal serpents and more.

Repair and restoration of antiques.

Antique instruments bought and sold.

New address:

140 E. Santa Clara St., \# 18

Arcadia, CA 91006

(818) 447-1904 

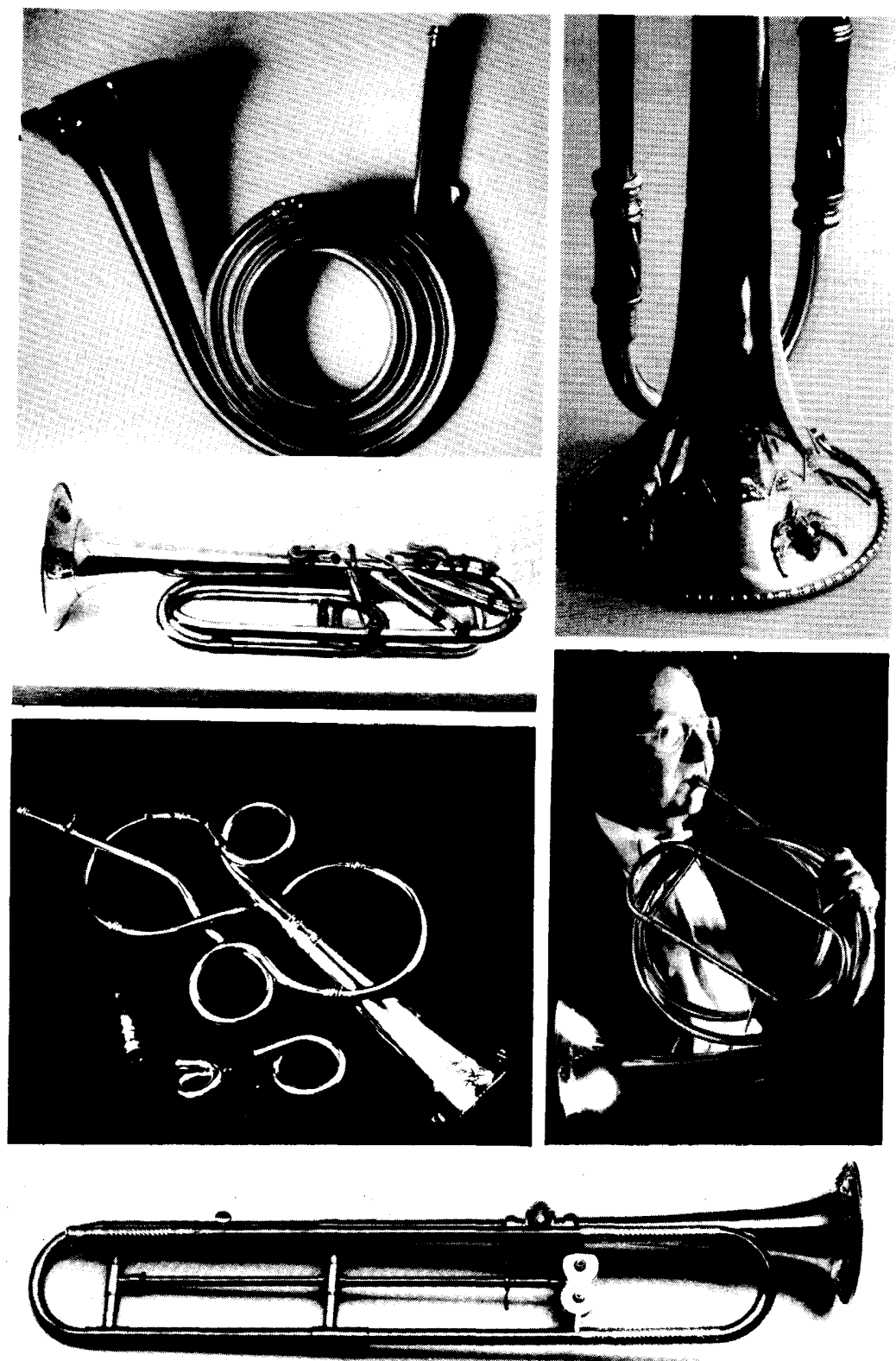

\section{JGHN WEBB}

54 Princedale Rd., London W1 1 4NL, England. Tel: 01-221 0274

Workshop: Padbrook, Chaddington Lane, Bincknoll,

Nr. Wootton Bassett, Swindon SN4 8QR, Wiltshire, England. Tel: 0793853171 